\title{
$\therefore$ \\ Perceived Stress and Sleep Quality of First Year Medical Students
}

IJCRR

Section: Healthcare

ISI Impact Factor

(2019-20): 1.628

IC Value (2019): 90.81

$\operatorname{SJIF}(2020)=7.893$

(c) (i) (8)

Copyright@IJCRR

\section{Jena SK ${ }^{1}$, Panigrahi AK², Pattnaik M³}

\author{
'Assistant Professor, Department of Physiology, Veer Surendra Sai Institute of Medical Sciences and Research, Burla, Sambalpur, Odisha, India; \\ ${ }^{2}$ Associate Professor, Department of Pharmacology, Veer Surendra Sai Institute of Medical Sciences and Research, Burla, Sambalpur, Odisha, India; \\ ${ }_{3}^{3}$ Associate Professor, Department of Physiology, SCB Medical College, Cuttack, Odisha, India.
}

\section{ABSTRACT}

Background: In the past few decades stress has been considered a major problem in medical students' life. Sleep abnormality is associated with cognitive function abnormalities. Stress is one of the prevalent factors which worsen sleep quality.

Aim: This study aimed to estimate the sleep quality of first-year medical students owing to perceived stress.

Method: This study was conducted after due approval from the institutional ethics committee. It was a cross-sectional study that included 144 subjects including 87 male and 57 female. Stress was assessed by perceived stress scale (PSS) and sleep quality was assessed by indicators designed by National Sleep Foundation (NSF). A P-value less than 0.05 was considered to be significant.

Result: $70.8 \%$ of subjects perceived moderate stress, $19.2 \%$ of subjects perceived low stress and $16 \%$ of subjects perceived high stress. On analysis, we found that some subjects sleep quality was inappropriate and most of them perceived severe stress.

Conclusion: Poor sleep quality was associated with severe stress in first-year medical students. This may affect the cognitive function that affects the carrier building.

Key Words: Perceived stress, Sleep quality, Medical students, Cognitive dysfunction

\section{INTRODUCTION}

Stress has been one of the most prevalent and important issues for medical students around the world for the past few decades. In very simple language it is the reaction of body and mind to challenges and threats. ${ }^{1}$ For any particular stressor, a person can experience either eustress (favourable stress) or distress (unfavourable stress). Various studies have reported that eustress has good effects on physiological functioning and facilitates the learning process, whereas distress has negative effects on physical and mental health. A higher level of stress for a prolonged period always has a detrimental effect on the body and mind. ${ }^{1}$ In a medical college contributing factors to the stressful environment are curriculum load, peer pressure, environmental factors and various types of examinations. ${ }^{2,3}$ The substantial negative effects of psychological stress contribute to poor performance of students in the classroom and clinical practices, the deficit in cognitive functions, illness, psychological disorders like anxiety, depression, and sleep disorders. ${ }^{4,5}{ }^{6}$ High-grade stress in students is also associated with poor health behaviours like eating unhealthy food, minimal exercise practices and inadequate sleep. Therefore in a single sentence, it can be explained, stress is responsible for poor physical, mental, behavioural health and academic performance. ${ }^{5}$ Sleep plays a vital role in the enhancement of working memory capacity and consolidation of memory. In a meta-analysis the researchers proposed their view that acute sleep deprivation is responsible for deficit in most cognitive domains like attention, working memory, and short-term memory. Insomnia is a sleep disorder reported by college students who experience psychological deficits. ${ }^{9}$ Delayed circadian rhythm is also a factor for poor sleep quality, especially during examination periods and both have been found to hurt academic performance. ${ }^{10,11}$ Stress is also another prevalent factor among medical students that worsens sleep quality. ${ }^{12}$ Considering the factors cited this study was proposed to estimate the sleep quality of the first year medical students owing to perceived stress.

\section{Corresponding Author:}

Jena SK, Assistant Professor, Department of Physiology, Veer Surendra Sai Institute of Medical Sciences and Research, Burla, Sambalpur- 768017, Mob: 7873720172; Email: drsunil80@gmail.com

ISSN: 2231-2196 (Print)

Received: 22.03 .2021
ISSN: 0975-5241 (Online)

Revised: 12.05 .2021
Accepted: 20.06.2021
Published: 20.11 .2021 


\section{MATERIAL AND METHOD}

This cross-sectional study was conducted in the Department of Physiology in a health institute in the eastern part of India between September 2019 and February 2020. The study was approved by the institutional ethics committee vide letter no 20006/Dt. 25.09.2000/IFO-9/20. Total 144 first-year MBBS students were included as study subjects among which 87 were male and 57 were female. Students were explained about the study protocol and its output. Healthy students were selected as subjects for this study. Students with a history of any disease, alcoholics were excluded from the study. For the selection of subjects 158 students were screened and finally, 149 subjects were selected. During the collection of data 5 subjects provided incomplete data for which they were excluded from the study. So finally 144 subjects were selected for data analysis.

A study tool in form of a questionnaire was designed and it was distributed among the students. Students were instructed properly to fill up the form honest and should not provide any wrong information. The questionnaire included sections A, B and C. Section A included demographic data, section $\mathrm{B}$ included the Perceived Stress Scale (PSS) questionnaire and section $\mathrm{C}$ included indicators of sleep quality according to the National Sleep Foundation (NSF). ${ }^{13,14}$ Proper instruction was given in each section of the questionnaire for the understanding and how to fill up the questionnaire. $20 \mathrm{~min}$ was given to them to fill up the questionnaire in presence of the principal investigator.

All questionnaires were put on data analysis. Subjects were between 19 to 23 years old. Among 144 subjects 87 were male and 57 were female. The stress score was calculated according to the instruction of PSS. PSS included 10 questions and each question had 5 options i.e. $0=$ never, $1=$ almost never, $2=$ sometimes, $3=$ fairly often and $4=$ very often. According to instruction in the PSS score of questions 4, 5, 7 and 8 was reversed in the following manner i.e. $0=4,1=3$, $2=2,3=1$ and $4=0$. Then the final score of each subject was calculated. Corresponding to their score perceived stress was categorized into low, moderate and high as shown in table 1. ${ }^{13}$

NSF derived four sleep quality indicators to assess the sleep quality and these are "sleep latency (min)", "Awakening after 5 minutes (episode)", "Wake after sleep onset (min)" and "sleep efficiency (\%)". Among the four indicators, each indicator can be used to assess sleep quality independently. NSF categorized sleep quality into appropriate, uncertain and appropriate taking into account the indicators of sleep as shown in table $2 .{ }^{14}$

Data analysis was done by statistical software SPSS 20. The significance of data was tested by the Chi-square test. A P- value less than 0.05 was considered to be significant. Generation of tables was done by Microsoft word.

\section{RESULT}

This study was completed among 87 male and 57 female subjects. Table 3 depicts the frequency distribution of subjects owing to perceived stress. $70.8 \%$ perceived moderate stress, $19.2 \%$ perceived low stress and $16 \%$ perceived high stress.

Table 4 depicts "sleep latency" as an indicator of sleep quality and analyzed with stress. From this analysis we found sleep quality of $96(66.6 \%)$ subjects was appropriate, 18 $(12.5 \%)$ subjects were uncertain and $30(20.8 \%)$ was inappropriate. Among the subjects having inappropriate sleep quality, $53.3 \%$ perceive high stress. This distribution was found to be significant.

Table 5 depicts "sleep efficiency" as an indicator of sleep quality and analyzed with stress. From this analysis we found sleep quality of 94 (65.2\%) subjects was appropriate, $24(16.6 \%)$ subjects were uncertain and $26(18 \%)$ was inappropriate. Among the subjects having inappropriate sleep quality, $50 \%$ perceive high stress. This distribution was found to be significant.

Table 6 depicts "awakening after 5 min" as an indicator of sleep quality and analyzed with stress. From this analysis we found sleep quality of 96 (66.6\%) subjects was appropriate, $30(20.8 \%)$ subjects were uncertain and $18(12.5 \%)$ was inappropriate. Among the subjects having inappropriate sleep quality, $66.6 \%$ perceive high stress. This distribution was found to be significant.

Table 7 depicts "wake after sleep onset" as an indicator of sleep quality and analyzed with stress. From this analysis we found sleep quality of $98(68 \%)$ subjects was appropriate, $22(15.2 \%)$ subjects were uncertain and $24(16.6 \%)$ was inappropriate. Among the subjects having inappropriate sleep quality, $87.5 \%$ perceive high stress. This distribution was found to be significant.

\section{DISCUSSION}

First-year medical students when joining the MBBS course, have a lot of ambitions and expectations. The curriculum is designed such that they have to adapt a lot of things during their whole period of study. Vast course burden, peer pressure, routine assessment and many more stressors put them in a situation that is not avoidable. ${ }^{15,16}$ Students having better coping mechanisms adapt to stress but those who are unable to cope with the situation, their body physiology is disturbed. In this study, we analyzed how perceived stress affect sleep quality in first-year medical students. 
This study suggested that $16 \%$ of subjects perceive high stress, 70.8\% moderate stress and 19.2\% low stress. Sleep quality was analyzed by four indicators i.e. sleep latency (min), sleep efficiency (\%), awakening after 5 minutes (episode), wake after sleep onset (min). Each indicator was used to analyze sleep quality owing to stress and we found that most of the subjects perceived high stress had inappropriate sleep. So this study suggested that increase stress level was associated with poor sleep quality.

Several studies observed that stress level and sleep quality are associated in the linear fashion that is when the stress level is high sleep quality is poor or sleep is inappropriate. They reported those persons to experience high-stress levels their sleep is inappropriate. ${ }^{17,18}$ Insomnia is a sleep disorder quite common nowadays. More stressed persons are more prone to develop insomnia. ${ }^{18}$ Many researchers did their studies on students and found that students having inappropriate sleep or poor sleep quality and perceived severe stress face problem in their academic achievement. They suggested that for students whose sleep quality is inappropriate their academic performance is poor. ${ }^{11,12,19}$ Some other studies reported a negative correlation between sleep disorder and the academic performance of students. ${ }^{20,21}$ When a person faces a challenge or stressor certain physiological response occurs leading to increased secretion of stress hormones. Stress response includes activation of hypo-thalamopituitary-adrenal axis and release of adrenaline and cortisol. ${ }^{22,23}$ Cortisol is a steroid hormone secreted from the adrenal cortex is under the control of circadian rhythm. Persons whose sleep quality is poor or inappropriate their circadian rhythm of cortisol secretion is affected. So a vicious cycle is generated and a negative impact is observed on the mental health of students. ${ }^{23}$ Adjustment in academic load, fear of failure in carrier, repetitive assessments and examinations could be the possible cause of sleep deprivation in medical students. ${ }^{23}$

\section{LIMITATION}

This study could be more effective if the sample size was more. We could not analyze the gender difference in sleep quality. This study was conducted in a single institute and further studies are essential including multiple institutions. We could not able to include other confounding factors like the socioeconomic status of subjects that influence the stress.

\section{CONCLUSION}

A low grade of stress is essential for performance but the high and severe grade of stress is always harmful. This study concluded that students who perceive severe grades of stress experience poor sleep quality which is harmful to their carrier. So necessary counselling is required to cope with the stress and to maintain a healthy life.

\section{Conflicts of Interest}

No conflicts of interest

\section{Source of Funding}

Nil

\section{ACKNOWLEDGEMENT}

The authors acknowledge the immense help received from the scholars whose articles are cited and included in references of this manuscript. The authors are also grateful authors and publishers of all those articles, journals and books from where the literature for the article has been reviewed and discussed.

\section{Author Contribution}

Jena SK - Conceive and design the study, data collection and analysis, manuscript writing.

Panigrahi SK - Statistical analysis, manuscript writing.

Pattnaik M - Manuscript writing, final correction of the manuscript

\section{REFERENCES}

1. Behere SP, Yadav R, Behere PB. A comparative study of stress among students of medicine, engineering, and nursing. Indian $\mathrm{J}$ Psychol Med. 2011;33(2):145-148.

2. Waqas A, Khan S, Sharif W, Khalid U, Ali A. Association of academic stress with sleeping difficulties in medical students of a Pakistani medical school: a cross-sectional survey. Peer J. 2015;3:e840.

3. Sreeramareddy CT, Shankar PR, Binu VS, Mukhopadhyay C, Ray B et al. Psychological morbidity, sources of stress and coping strategies among undergraduate medical students of Nepal. BMC Med Educ. 2007;7(1):26.

4. Malathi A, Damodaran A. Stress due to exams in medical students- the role of yoga. Indian J. Physiol. Pharmacol. 1999;43(2):218-224.

5. Brougham RR, Zail CM, Mendoza CM, Miller JR. Stress, sex differences, and coping strategies among college students. Curr Psychol. 2009;28(2):85-97.

6. Azim SR, Baig M. Frequency and perceived causes of depression, anxiety and stress among medical students of a private medical institute in Karachi: a mixed-method study. J Pak Med Assoc. 2019;69(6):840-845.

7. Fenn KM, Hambrick DZ. Individual differences in working memory capacity predict sleep-dependent memory consolidation. J. Exp. Psychol. Gen. 2012;141(3):404-410.

8. Lim J, Dinges DF. A meta-analysis of the impact of short-term sleep deprivation on cognitive variables. Psychol Bull 2010;136(3):375-389.

9. Chang PP, Ford DE, Mead LA, Cooper-Patrick L, Klag MJ. Insomnia in young men and subsequent depression. The Johns Hopkins precursors study. Am J Epidemiol. 1997;146(2):105-114.

10. Phillips AJK, Clerx WM, O'Brien CS, Sano A, Barger LK et al. Irregular sleep/wake patterns are associated with poorer aca- 
demic performance and delayed circadian and sleep/wake timing. Sci Rep. 2017;7(1):3216.

11. AhrbergK, DreslerM, NiedermaierS, SteigerA, GenzelL. The interaction between sleep quality and academic performance. J Psychiatr Res. 2012;46(12):1618-1622.

12. Åkerstedt T, Orsini N, Petersen H, Axelsson J, Lekander M et al. Predicting sleep quality from stress and prior sleep - A study of day-to-day covariation across six weeks. Sleep Med. 2012;13(6):674-679.

13. Cohen S, Kamarck T, Mermelstein, R. A global measure of perceived stress. J Health Soc Behav. 1983;24(4),385-396.

14. Hirshkowitz M, Whiton K, Albert SM, Alessi C, Bruni O et al. National Sleep Foundation's sleep time duration recommendations: methodology and results from the summary. Sleep Health. 2015;1(1):40-43.

15. Dahlin M, Joneborg N, Runeson B. Stress and depression among medical students: A cross-sectional study. Med Educ. 2005;39(6):594-604.

16. Castaldelli-Maia JM, Martins SS, Bhugra D, Machado MP, Andrade AG et al. Does ragging play a role in medical student depression — cause or effect? J Affect Disord. 2012;139(3):291297.
17. Morin CM, Rodrigue S, Ivers H. Role of stress, arousal and coping skills in primary insomnia. Psychosom Med. 2003;65(2):259-267.

18. Zunhammer M, Eichhammer P, Busch V. Sleep quality during exam stress: The role of alcohol, caffeine and nicotine. PLoS One. 2014;9(10):e109490.

19. Stewart SM, LamTH, BetsonCL, WongCM, WongAM. A prospective analysis of stress and academic performance in the first two years of medical school. Med. Educ. 1999;33(4):243-250.

20. Bahammam AS, Alaseem AM, Alzakri AA, Almeneessier AS, Sharif MM. The relationship between sleep and wake habits and academic performance in medical students: a cross-sectional study. BMC Med. Educ. 2012;12:61

21. Abdulghani HM, Alrowais NA, Bin-SaadNS, Al-Subaie NM, Haji AM et al. Sleep disorder among medical students: relationship to their academic performance. Med. Teach. 2012;34(Suppl 1): S37-41.

22. Leproult R, Copinschi G, Buxton O, Van Cauter E. Sleep loss results in an elevation of cortisol levels the next evening. Sleep 1997;20(10):865-870.

23. Shah M, Hasan S, Malik S, Sreeramareddy CT. Perceived stress, sources and severity of stress among medical undergraduates in a Pakistani medical school. BMC Med. Educ. 2010;10(1):2.

Table 1: Category of Stress

\begin{tabular}{lccc} 
Category & Low & Moderate & High \\
Score & $0-13$ & $14-26$ & $27-40$ \\
\hline
\end{tabular}

Grading of stress based on stress score

Table 2: Sleep quality indicators and sleep quality

\begin{tabular}{lccc} 
Sleep quality & Appropriate & Uncertain & Inappropriate \\
Sleep latency (min) & $\leq 30$ & $31-45$ & $\geq 46$ \\
Awakening after 5 min (episode) & $\leq 1$ & $2-3$ & $\geq 4$ \\
Wake after sleep onset (min) & $0-20$ & $21-40$ & $\geq 40$ \\
Sleep efficiency (\%) & $\geq 85$ & $65-84$ & $\leq 64$ \\
\hline
\end{tabular}

Classification of sleep quality

Table 3: Frequency distribution of subjects owing to Stress

$\begin{array}{lcccc}\text { Variable } & \begin{array}{c}\text { Low } \\ \text { Number (\%) }\end{array} & \begin{array}{c}\text { Moderate } \\ \text { Number (\%) }\end{array} & \begin{array}{c}\text { High } \\ \text { Number (\%) }\end{array} & \begin{array}{c}\text { Total } \\ \text { Number (\%) }\end{array} \\ \text { Male } & 14(9.7) & 64(44.4) & 9(6.3) & 87(39.6) \\ \text { Female } & 5(3.5) & 38(26.4) & 14(9.7) & 57(60.4) \\ \text { Total } & 19(13.2) & 102(70.8) & 23(16) & 144(100)\end{array}$

Distribution of subjects in different grading of stress

Table 4: Sleep latency

\begin{tabular}{lccccc} 
Variable & Appropriate & Uncertain & Inappropriate & Total & $\mathbf{p}$ \\
Low & 15 & 1 & 3 & 19 & \\
Moderate & 77 & 14 & 11 & 102 & 0.000 \\
High & 4 & 3 & 16 & 23 & \\
Total & 96 & 18 & 30 & 144 & \\
\hline
\end{tabular}

Sleep quality of subjects based on sleep latency. 
Table 5: Sleep efficiency

\begin{tabular}{lccccc} 
Variable & Appropriate & Uncertain & Inappropriate & Total & p \\
Low & 15 & 4 & 0 & 19 & \\
Moderate & 71 & 18 & 13 & 102 & 0.000 \\
High & 8 & 2 & 13 & 23 & \\
Total & 94 & 24 & 26 & 144 & \\
\hline
\end{tabular}

Sleep quality of subjects based on sleep efficiency

Table 6: Awakening after 5 minutes

\begin{tabular}{lccccc} 
Variable & Appropriate & Uncertain & Inappropriate & Total & p \\
Low & 15 & 3 & 1 & 19 & \\
Moderate & 75 & 22 & 5 & 102 & 0.000 \\
High & 6 & 5 & 12 & 23 & \\
Total & 96 & 30 & 18 & 144 & \\
\hline
\end{tabular}

Sleep quality of subjects based on waking after 5 minutes

Table 7: Wake after sleep onset

\begin{tabular}{lccccc} 
Variable & Appropriate & Uncertain & Inappropriate & Total & p \\
Low & 16 & 3 & 0 & 19 & \\
Moderate & 80 & 19 & 3 & 102 & o.ooo \\
High & 2 & 0 & 21 & 23 & \\
Total & 98 & 22 & 24 & 144 & \\
\hline
\end{tabular}

Sleep quality of subjects based on wake after sleep onset 